\title{
Experimental investigation on shore hardness of barrel-finished FDM patterns
}

\author{
RUPINDER SINGH*, ALOK TRIVEDI and SUNPREET SINGH \\ Department of Production Engineering, Guru Nanak Dev Engineering College, Ludhiana 141006, India \\ e-mail: rupindersingh78@yahoo.com
}

MS received 19 December 2014; revised 5 November 2015; accepted 19 January 2017; published 2 August 2017

\begin{abstract}
Barrel finishing (BF) process is widely used to improve the surface finish and dimensional features of metallic and non-metallic parts using different types of media. As a matter of fact the change in shore hardness ( $\mathrm{SH}$ ) features of fused deposition modelling (FDM)-based master pattern is one of the important considerations from its service point of view. The main objective of present research work is to investigate the effect of BF process on SH of acrylonitrile-butadiene-styrene (ABS)-based master patterns prepared by FDM. Six controllable parameters of FDM and BF, namely, geometry of prototype, layer density, part orientation, types of BF media, weight of media and finish cycle time, were studied using Taguchi's L18 orthogonal array in order to find their effect on SH of master pattern. Results indicated that process parameters significantly affect the SH of master patterns. It has been found that FDM part layer density contributed the maximum (about $67.52 \%$ ) for $\mathrm{SH}$ of master patterns.
\end{abstract}

Keywords. Fused deposition modelling; barrel finishing; shore hardness; Taguchi; optimization.

\section{Introduction}

Nowadays, rapid prototyping (RP) is the most efficient tool for rapid design and testing of new products [1]. This technology is no longer expensive and more and more companies are using it at all stages of the design process, from market evaluation and conceptual design to final verification and manufacturing analysis. By the RP process it is possible to build parts having complicated geometry in the least possible time without incurring extra cost due to the absence of tooling [2]. Another advantage with RP is the scope of unlimited design iterations on digital data [3]. Many researchers had employed RP technique to assist the investment casting (IC) process for reducing the cost and lead times of the conventional IC process [4-6]. Fused deposition modelling (FDM) is the latest in RP and it offers numerous benefits, including a good variety of materials available, easy material change, low maintenance costs, quick production of thin parts and close geometrical tolerances $( \pm 0.1 \mathrm{~mm})$ [7]. Furthermore, it needs no supervision, uses non-toxic filament materials and has advantages of compact size and low operational temperature. It is likely to consider FDM as a green manufacturing process as the plastic-based waste can be easily recycled. However, there exist some laminations that have poor surface roughness due to the staircase effect (the angle between the vertical axis and surface tangents) in manufacturing [6].

*For correspondence
Various mass finishing operations such as barrel finishing (BF) can be employed for the improvement of the surface finish in additive manufacturing industries $[8,9]$. $\mathrm{BF}$ is also considered as a green process as it is non-hazardous and the media can be re-used. The wooden medium rubs against the irregularities present on the surface; this improves the surface finish of the part. During the rubbing mechanism, the dimensional features of the parts may suffer as the material is being removed from the surface in the form of very fine chips. It has been practically found that besides improving the surface finish, it also has significant effect on the shore hardness $(\mathrm{SH})$. As a matter of fact, change in $\mathrm{SH}$ of master pattern is a very important consideration when the parts serve as an assembly element. Generally, it is assumed that the part having a higher hardness value will resist its abrasion, erosion, adhesion, etc. Further, the high $\mathrm{SH}$ of plastic pattern will eliminate the chance of IC tree damage during handling. A pictorial view of the $\mathrm{BF}$ machine used in the present research work is shown in figure 1.

The BF machine consists of a rotary drive mechanism and an open-topped bowl. Mass finishing is initiated by loading the work pieces and media (commonly called the workload) from the top into the bowl. The disk rotates and drives the workload in a helical path around the centreline of the bowl [10]. Figure 2 shows the 2-D views of BF wooden media used in the present research work. Abrasive powder (sodium bicarbonate) and abrasive paste of aliphatic hydrocarbons were also used along with BF media. 


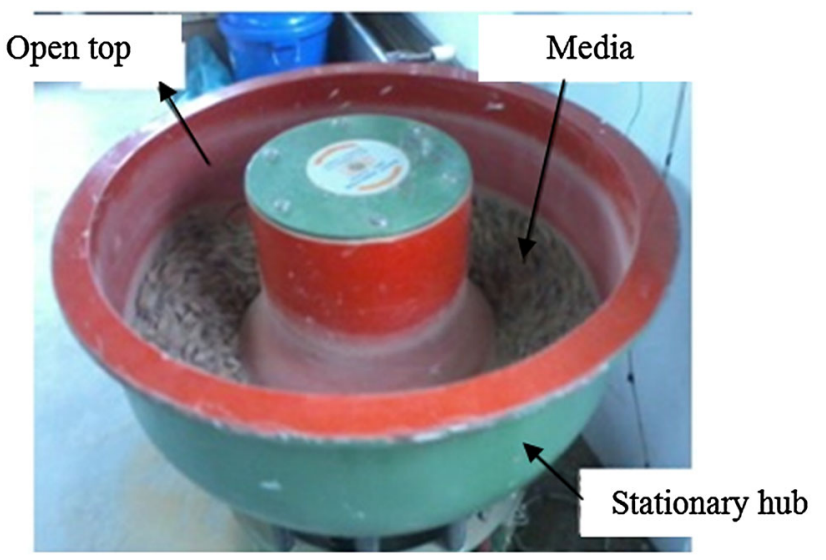

Figure 1. Pictorial view of BF machine.

In the present work, abrasive powder and abrasive paste (both $10 \mathrm{~g} / \mathrm{kg}$ of media) were used with pyramid-shaped media and cube-shaped media, respectively. In the current research work, six controllable parameters of FDM and BF (geometry of prototype, layer density, part orientation, types of BF media, weight of media and finish cycle time) were selected to study their effect on the SH of the acrylonitrile-butadiene-styrene (ABS)-based master pattern by conducting experiments as per Taguchi's L18 orthogonal array.

\section{Experimentation}

In the present investigation, standard benchmarks of cubical, spherical and conical shapes (2-D views shown in figure $3 \mathrm{a}-\mathrm{c}$ ) were prepared by FDM. The reason behind the selection of these benchmark geometries is the fact that almost all complex geometries consist of curves, lengths and angles, which are approximately considered in the present study. The prototyping of the benchmark geometries was carried out on a uPrint-SE system (make: Stratasys Inc) at three available densities while the volume of all three geometries was kept the same.

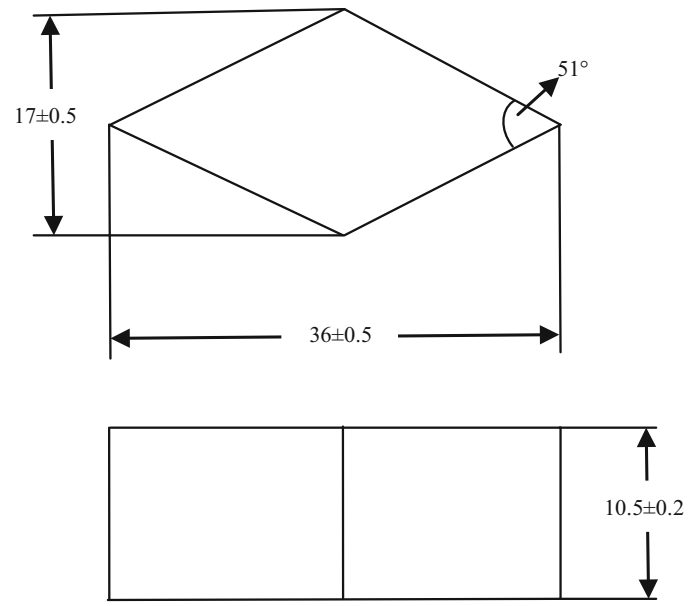

(a)

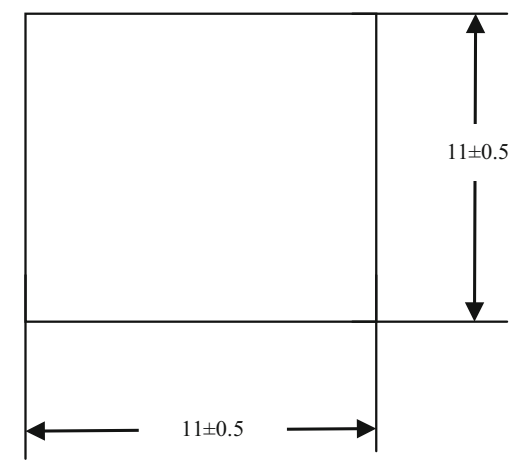

(b)

Figure 2. 2-D view of wooden media of (a) pyramidal shape and (b) cubical shape. Note: All units are in $\mathrm{mm}$.

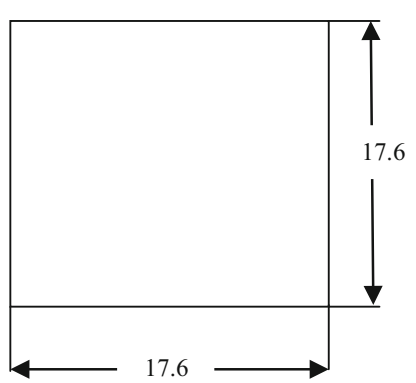

(a)

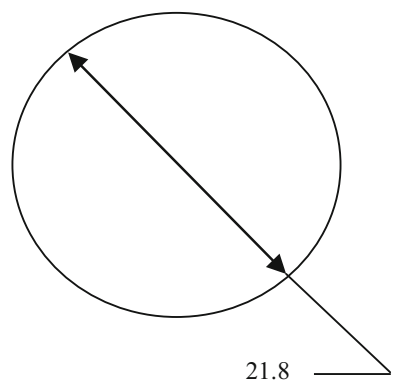

(b)

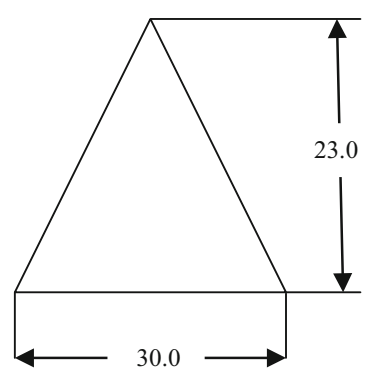

(c)

Figure 3. 2-D view of benchmarks: (a) cube, (b) sphere and (c) cone. Note: All units are in mm. 
Table 1. List of process parameters and their levels.

\begin{tabular}{lccc}
\hline Parameters & Level 1 & Level 2 & Level 3 \\
\hline Shape of BF media $(A)$ & Pyramid & Cube & - \\
Geometry of FDM parts $(B)$ & Cube & Sphere & Cone \\
Layer density $(C)$ & Low & High & Solid \\
Part orientation $(D)$ & $30^{\circ}$ & $15^{\circ}$ & $0^{\circ}$ \\
BF cycle time $(E)$ & 2 & 3 & 4 \\
BF media weight $(F)$ & 10 & 15 & 20 \\
\hline
\end{tabular}

Table 2. Design matrix used in the experimentation.

\begin{tabular}{|c|c|c|c|c|c|c|}
\hline S1. no. & $A$ & $B$ & $C$ & $D$ & $E$ & $F$ \\
\hline 1 & Pyramid & Cube & Low & $30^{\circ}$ & 2 & 10 \\
\hline 2 & Pyramid & Cube & High & $15^{\circ}$ & 3 & 15 \\
\hline 3 & Pyramid & Cube & Solid & $0^{\circ}$ & 4 & 20 \\
\hline 4 & Pyramid & Sphere & Low & $30^{\circ}$ & 3 & 15 \\
\hline 5 & Pyramid & Sphere & High & $15^{\circ}$ & 4 & 20 \\
\hline 6 & Pyramid & Sphere & Solid & $0^{\circ}$ & 2 & 10 \\
\hline 7 & Pyramid & Cone & Low & $15^{\circ}$ & 2 & 20 \\
\hline 8 & Pyramid & Cone & High & $0^{\circ}$ & 3 & 10 \\
\hline 9 & Pyramid & Cone & Solid & $30^{\circ}$ & 4 & 15 \\
\hline 10 & Cube & Cube & Low & $0^{\circ}$ & 4 & 15 \\
\hline 11 & Cube & Cube & High & $30^{\circ}$ & 2 & 20 \\
\hline 12 & Cube & Cube & Solid & $15^{\circ}$ & 3 & 10 \\
\hline 13 & Cube & Sphere & Low & $15^{\circ}$ & 4 & 10 \\
\hline 14 & Cube & Sphere & High & $0^{\circ}$ & 2 & 15 \\
\hline 15 & Cube & Sphere & Solid & $30^{\circ}$ & 3 & 20 \\
\hline 16 & Cube & Cone & Low & $0^{\circ}$ & 3 & 20 \\
\hline 17 & Cube & Cone & High & $30^{\circ}$ & 4 & 10 \\
\hline 18 & Cube & Cone & Solid & $15^{\circ}$ & 2 & 15 \\
\hline
\end{tabular}

In the recent years, the Taguchi technique has been immensely used to optimize process and product design, based on comprehensive experimental investigation [11]. The primary advantages of the design of experiments (DOE) using Taguchi's technique include simplification of experimental plan and feasibility of study of interaction effects among the different parameters. The process parameters involved with the FDM system are layer thickness, speed of deposition, type of material, extrusion temperature, etc. However, the FDM uPrint-SE system does not permit the afore-mentioned options; hence, the available parameters such as density of FDM patter and orientation were considered in the present study. Table 1 shows the process parameters and levels selection for the study. A design matrix based on an L18 orthogonal array (see table 2) was chosen to account for factors and levels.

\section{Results and discussion}

Generally, an SH tester measures the resistance of a material to indentation. The $\mathrm{SH}$ tester (looks like a conventional pressure gauge) has a spring-loaded indenter at one end and space for the application of load on the other end. During testing, the indenter is pushed into the plastic surface normally. Once the gauge is pressed firmly against the plastic surface the indenter will penetrate as far as it can. The ASTM-2240 standard was followed for testing the $\mathrm{SH}$ of the benchmark components [12]. Accordingly, the $\mathrm{SH}$ tester (A scale) was used in the present research work as shown in figure 4 . The $\mathrm{SH}$ tester calibrates the spring force and displays the same digitally. The $\mathrm{SH}$ of specimens was measured three times on different contours in order to reduce the measurement error.

Table 3 shows the observations for $\mathrm{SH}$, where R1-R3 show the three repetitions of experiments. Means and signal to noise $(S / N)$ response has been analysed for $\mathrm{SH}$ on 'larger is better'. The means and $S / N$ graphs for $\mathrm{SH}$ are shown in figures 5 and 6 , respectively.
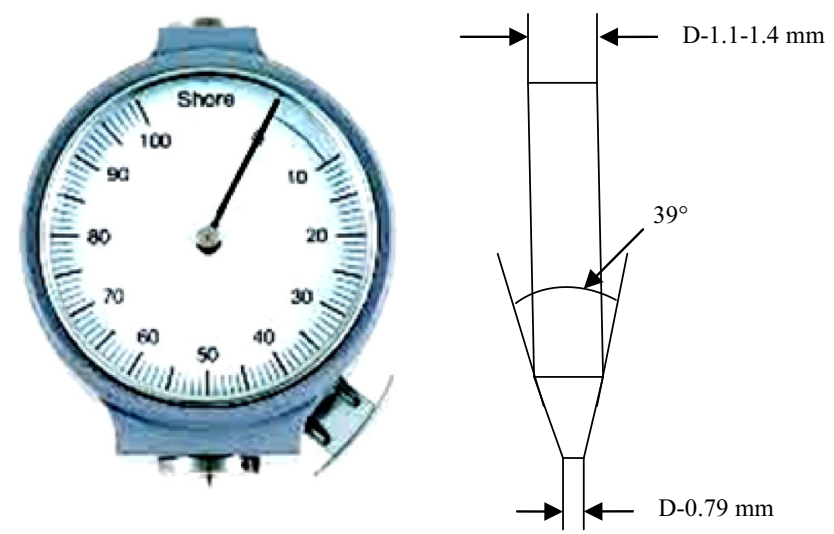

Figure 4. $\mathrm{SH}$ tester and $\mathrm{SH}$ indenter specification of 'A' scale.

Table 3. Observation for $\mathrm{SH}$.

\begin{tabular}{llll}
\hline & & SH & \\
\cline { 2 - 4 } Exp. no. & R1 & R2 & R3 \\
\hline 1 & 84 & 85 & 86 \\
2 & 90 & 89 & 90 \\
3 & 92 & 90 & 91 \\
4 & 84 & 83 & 82 \\
5 & 91 & 90 & 89 \\
6 & 92 & 91 & 90 \\
7 & 88 & 89 & 90 \\
8 & 89 & 90 & 91 \\
9 & 94 & 93 & 93 \\
10 & 86 & 85 & 86 \\
11 & 91 & 90 & 92 \\
12 & 91 & 92 & 90 \\
13 & 84 & 84 & 83 \\
14 & 85 & 86 & 86 \\
15 & 93 & 92 & 93 \\
16 & 89 & 88 & 90 \\
17 & 92 & 91 & 91 \\
18 & 92 & 93 & 91 \\
\hline
\end{tabular}




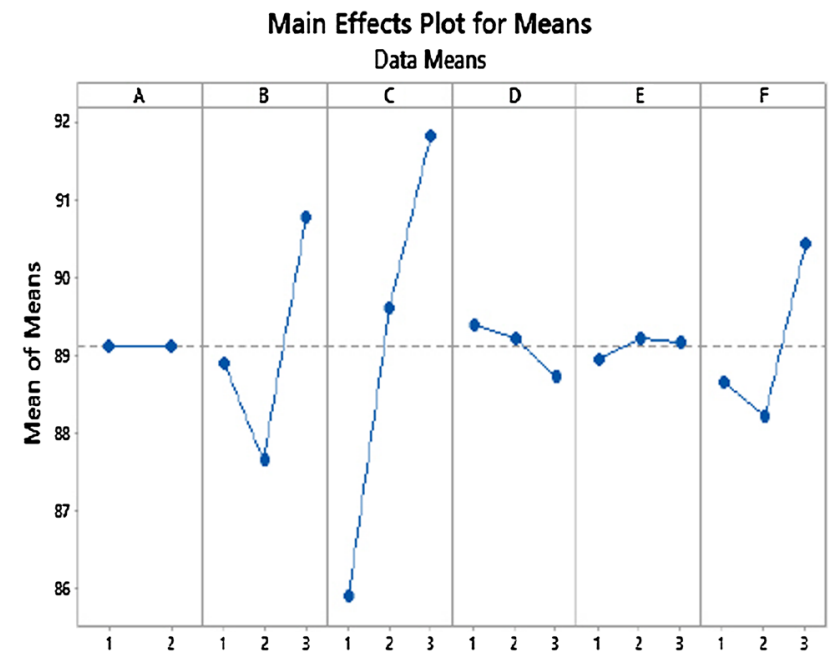

Figure 5. Means graph for $\mathrm{SH}$.

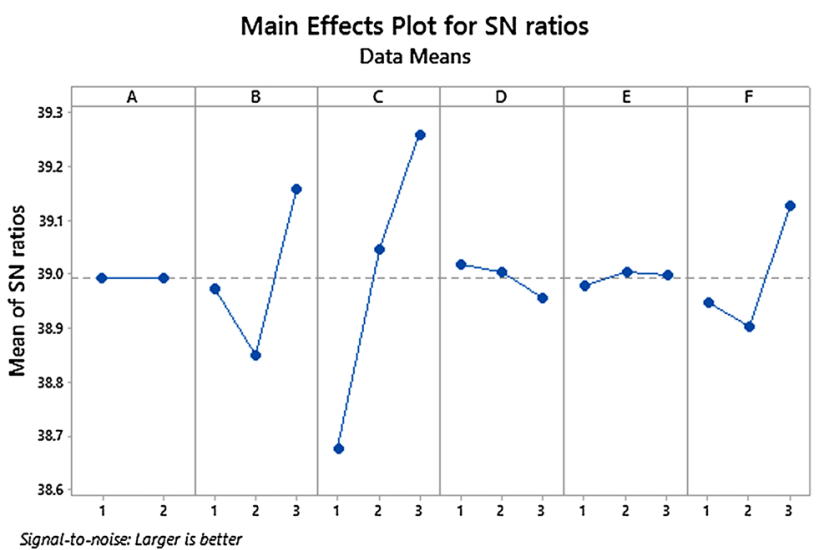

Figure 6. $S / N$ ratio graph for $\mathrm{SH}$.

In figure 6, it is observed that for parameter ' $C$ ' the peak $S / N$ ratio is obtained at the 3 rd level. This is due to the fact that on changing the density of FDM pattern, i.e., parameter $C$, the interlayer gap between the adjacent layers is changed. The pattern prepared with solid density has a dense interlayer structure, due to which the $\mathrm{SH}$ value is high. Further, the air gap between two adjacent layers was reduced as the distance between the layers reduced. The percentage contribution of parameter $C$ is about $67.52 \%$ (see figure 7). However, from Analysis of Variance (ANOVA), it has been found that none of the input process parameters except parameters $B$ and $C$ contribute to $\mathrm{SH}$ of the patterns. Table 4 shows the ANOVA table.

The optimized settings of process parameters are shown in table 5. Based on the optimized parametric settings a confirmatory experiment was conducted, and the final $\mathrm{SH}$ resulted into ' 95 '. The percentage improvement for $\mathrm{SH}$ was calculated as follows:

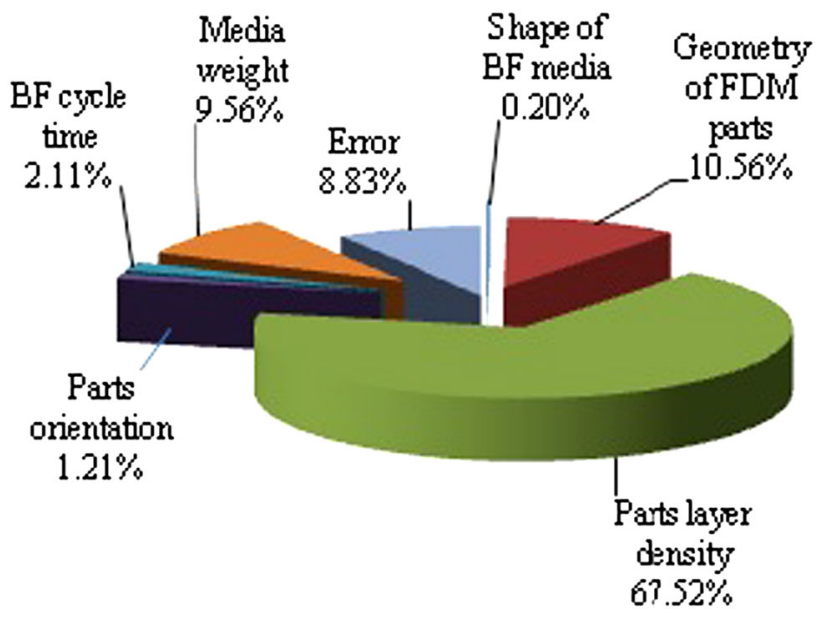

Figure 7. Percentage contribution of input parameters in $\mathrm{SH}$.

Table 4. ANOVA table for SH.

\begin{tabular}{lccccc}
\hline Source & DOF & Sum of squares & Variance & $F$-value & $P$ \\
\hline$A$ & 1 & 0 & 0 & 0 & 1.00 \\
$B$ & 2 & 29.48 & 14.74 & 7.68 & 0.02 \\
$C$ & 2 & 108.25 & 54.12 & 28.20 & 0.001 \\
$D$ & 2 & 1.44 & 0.72 & 0.38 & 0.702 \\
$E$ & 2 & 0.25 & 0.13 & 0.07 & 0.935 \\
$F$ & 2 & 16.53 & 8.29 & 4.32 & 0.069 \\
Error & 6 & 11.51 & 1.92 & - & - \\
\hline
\end{tabular}

Table 5. Best process parameters.

\begin{tabular}{lccccc}
\hline$A$ & $B$ & $C$ & $D$ & $E$ & $F$ \\
\hline 2 & 3 & 3 & 1 & 2 & 3 \\
Cube & Cone & Solid & $30^{\circ}$ & $3 \mathrm{~h}$ & $20 \mathrm{~kg}$ \\
\hline
\end{tabular}

percentage improvement

$$
=[(\text { initial SH }- \text { final SH }) / \text { initial SH }] \times 100 \text {. }
$$

The percentage improvement in $\mathrm{SH}$ was found to be $13.09 \%$.

\subsection{Scanning electron microscopy analysis}

Scanning electron microscopy (SEM) analysis of the barrelfinished FDM patterns has been carried out in order to find out the various changes encountered in the patterns after the finishing process. Figure 8 shows the SEM micrographs of barrel-finished FDM patterns. On comparing the various micrographs, it has been found that in Exp. no. 1 the waviness presented at the surface of FDM patterns is high, due to which the SH indenter may easily penetrate into the material and hence lead to incorrect hardness measurement. 


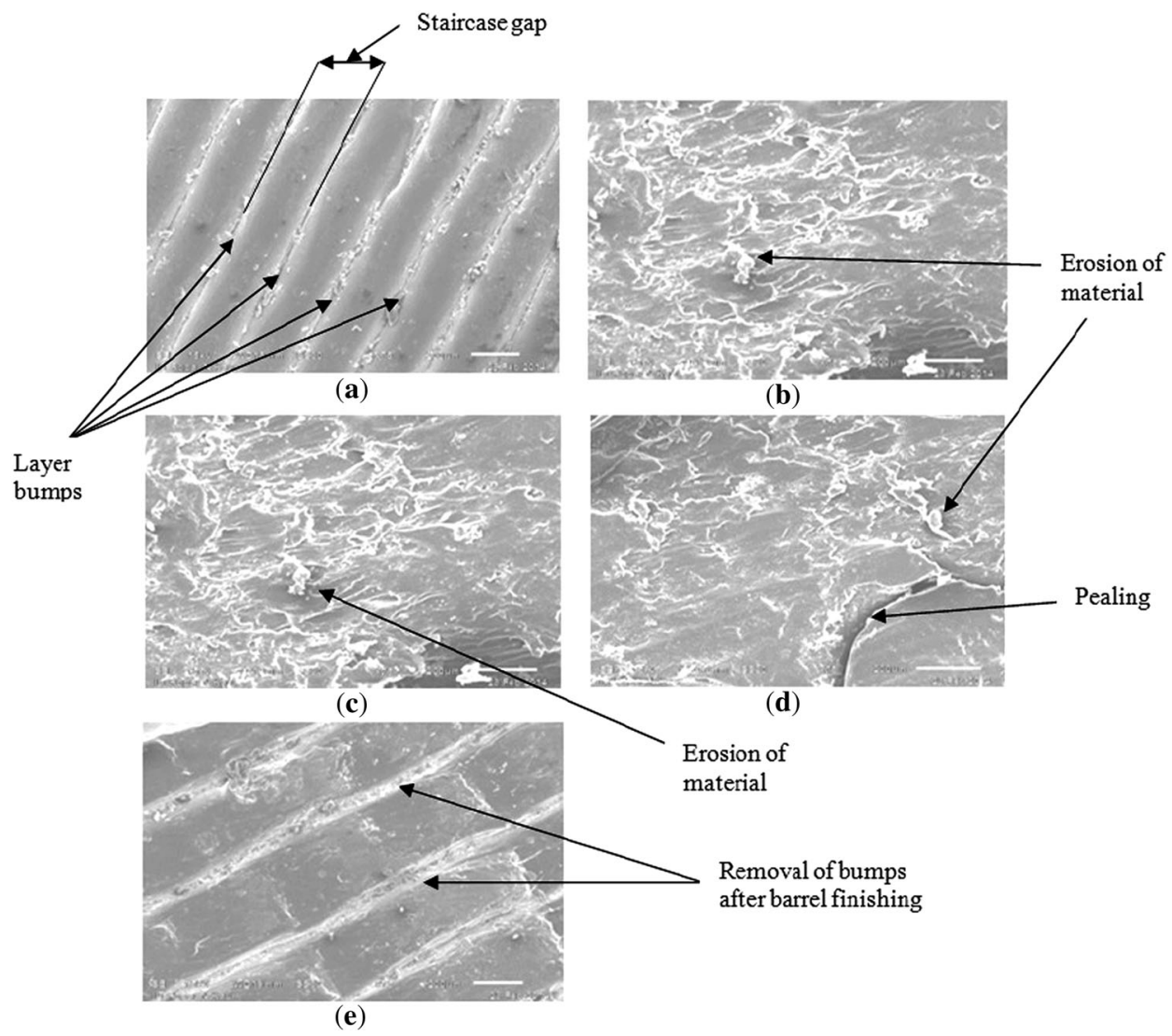

Figure 8. SEM micrographs of barrel-finished FDM patterns (at 200×).

In the pilot experimentation, it has been found that when the wooden media weight is above $20 \mathrm{~kg}$, more material gets peeled out. The heavy media loading results in erosion of the material. It has been observed that the erosion starts with the removal of the irregularities and creation of new irregularities. Figure 8a shows a micrograph of un-finished cube-shaped FDM pattern. It can be seen that the waviness presented on the surface of the patterns is more, due to which the resulting surface roughness value is also high. Figure $8 \mathrm{~b}$ and $\mathrm{c}$ shows a micrograph of cube-shaped FDM pattern after BF with 10 and $15 \mathrm{~kg}$ media load, respectively. It has been observed that the finishing of the patterns was accomplished with the erosion of the irregularities from the surface. However, in case of figure $8 \mathrm{~d}$, it is observed that besides erosion of material, the formation of new irregularities has been started.

The SEM analysis carried out on the part fabricated and finished at the optimized settings, given as figure 8e, resulted in the formation of an almost flat surface. Generally, the parts fabricated in low density option possess lesser hardness due to the fact that the layers just beneath the top surface have less density, which easily allows the indenter to penetrate; hence SH is less. Similarly, an opposite trend follows for the parts fabricated in solid density option of FDM system.

\section{Conclusions}

Results of the study suggest that BF operation can be adopted as an efficient method for improving the surface finish of the FDM patterns without any adverse effect on the dimensional accuracy and the SH of the patterns. It has been found from ANOVA analysis that only geometry of FDM parts and part layer density have significant effect on the $\mathrm{SH}$ of the patterns. Both of these parameters are not related to BF operation. Further, from SEM analysis, it has been found that the material starts to peel off under heavy loading of wooden media. The confirmatory experiment conducted at the proposed optimum settings highlighted $13.09 \%$ improvement.

\section{References}

[1] Syam W P, Mannan M A and Al-Ahmari A M 2011 Rapid prototyping and rapid manufacturing in medicine and dentistry. Virtual Phys. Prototyp. 6: 79-109

[2] Marcincinova L N and Kuric I 2012 Basic and advanced materials for fused deposition modeling rapid prototyping technology. Manuf. Ind. Eng. 11: 24-27 
[3] Sivadasan M, Singh N K and Sood A K 2012 Investment casting-rapid tooling approach. Int. J. Mech. Ind. Eng. 1: 99-103

[4] Dong Y, Dou Y B and Zhang D 2011 Determination of interfacial heat-transfer coefficient during investment-casting process of single-crystal blades. J. Mater. Process. Technol. 211: 2123-2131

[5] Singh R and Singh S 2013 Effect of process parameters on surface hardness, dimensional accuracy and surface roughness of investment cast components. J. Mech. Sci. Technol. 27: 191-197

[6] Singh R 2011 An overview of three dimensional printing for casting applications. Int. J. Precis. Technol. 2: 93-116

[7] Chua C K, Chou S M and Wong T S 1998 A study of state of the art rapid prototyping technologies. Int. J. Adv. Manuf. Technol. 14: 146-152
[8] Boschetto A, Giordano V and Veniali F 2013 3D roughness profile model in fused deposition modelling. Rapid Prototyp. J. 19: 240-252

[9] Boschetto A, Giordano V and Veniali F 2013 Microremoval modeling of surface roughness in barrel finishing. Int. J. Adv. Manuf. Technol. 69: 2343-2354

[10] Cariapa V, Park H, Kim J, Cheng C and Evaristo A 2008 Development of a metal removal model using spherical ceramic media in a centrifugal disk mass finishing machine. Int. J. Adv. Manuf. Technol. 39: 92-106

[11] Ross P J 1996 Taguchi techniques for quality engineering, 2nd edn. New York: McGraw Hill International

[12] ASTM Organization 2010 Standard test method for rubber property—durometer hardness. ASTM-D2240-05 